\title{
EXISTENCE OF AN UNBOUNDED SOLUTION FOR MULTI-POINT BOUNDARY VALUE PROBLEMS OF FRACTIONAL DIFFERENTIAL EQUATIONS ON AN INFINITE DOMAIN
}

\section{YOUSEF GHOLAMI}

Abstract. In this paper, considering the fractional boundary value problem

$$
\left\{\begin{array}{l}
D_{0^{+}}^{\alpha} u(t)+a(t) f\left(t, u(t), u^{\prime}(t)\right)=0 ; \quad t \in(0, \infty), \alpha \in(2,3), \\
u(0)=u^{\prime}(0)=0, \quad \lim _{t \rightarrow \infty} D_{0^{+}}^{\alpha-1} u(t)=\left.\sum_{i=1}^{m} \beta_{i} D_{0^{+}}^{\alpha-1} u(t)\right|_{t=\xi_{i}} \\
0<\xi_{1}<\xi_{2}<\ldots<\xi_{m}<\infty, \quad \beta_{i} \in \mathbb{R},
\end{array}\right.
$$

where $D_{0^{+}}^{\alpha}$ represents Riemann-Liouville fractional derivative of order $\alpha$ and using famous Leray-Schauder Nonlinear Alternative theorem, we will obtain an unbounded solution of above BVP. At the end some examples illustrate.

Mathematics subject classification (2010): Primary: 34A08, 34B18; Secondary: 34B10, 34B40.

Keywords and phrases: Multi-point boundary value problem, Riemann-Liouville fractional derivative, unbounded solution, infinite interval, fixed point theorem.

\section{REFERENCES}

[1] A. A. Kilbas, H. M. Srivastava, J. J. Trujillo, Theory and Applications of fractional Differential Equations, North-Holland mathematics studies, Elsvier science, 204 (2006).

[2] K. S. Miller, B. Ross, An Introduction to fractional calculus and fractioal differential equation, John Wiley, New York, (1993).

[3] I. Poudlobny, Fractional Differential Equations, Mathematics in Science and Applications, Academic Press, 19 (1999).

[4] Sinua Liang, Jihui Zhang, Existence of multiple positive solutions for m-point fractional boundary value problems on an infinite interval, Mathematical and Computer modelling, 54 (2011), 1334 1346.

[5] X. ZHAO, W. GE, Unbounde solutions for a fractional boundary value problem on the infinite interval, Acta Appl Math, 109 (2010), 495-505.

[6] KAZEM GHANBARI, YousEF GHOlami, Existence and multiplicity of positive solutions for $m$-point nonlinear fractional differential equations on the half line, Electronic Journal of Differential equations, Vol. 2012 (2012), No. 238, pp. 1-15.

[7] KaZem Ghanbari, Yousef Gholami, Existence and nonexistence results of positive solutions for nonlinear fractional eigenvalue problem, Journal of Fractional Calculus and Applications, Vol. 4 (2013), No. 2, pp. 1-12.

[8] Kazem Ghanbari, Yousef Gholami, And Hanif Mirzaei, Existence and multiplicity results of positive solutions for boundary value problems of nonlinear fractional differential equations, Dynamics of Continuous, Discrete and Impulsive Systems, Series A: Mathematical Analysis 20 (2013), $543-558$.

[9] SHUQIN ZHANG, Unbounded solutions to a boundary value problem of fractional order on the halfline, Computers and mathematics with Applications, 61 (2011), 1079-1087. 